Journal of

Molecular Microbiology

and Biotechnology

\title{
The Vibrio cholerae Mrp System: Cation/Proton Antiport Properties and Enhancement of Bile Salt Resistance in a Heterologous Host
}

\author{
Judith Dzioba-Winogrodzki ${ }^{a}$ Olga Winogrodzki ${ }^{a}$ Terry A. Krulwich ${ }^{b}$ \\ Markus A. Boin ${ }^{c}$ Claudia C. Häse ${ }^{c}$ Pavel Dibrov ${ }^{a}$ \\ ${ }^{a}$ Department of Microbiology, University of Manitoba, Winnipeg, Man., Canada; ${ }^{b}$ Department of Pharmacology \\ and Biological Chemistry, Mount Sinai School of Medicine, New York, N.Y., and 'Department of \\ Biomedical Sciences, College of Veterinary Medicine, Oregon State University, Corvallis, Oreg., USA
}

\section{Key Words}

Vibrio cholerae $\cdot \mathrm{Mrp} \cdot \mathrm{Na}^{+}\left(\mathrm{Li}^{+}\right)\left(\mathrm{K}^{+}\right) / \mathrm{H}^{+}$antiporter $\cdot$

Bile resistance $\cdot$ Heterologous expression

\begin{abstract}
The mrp operon from Vibrio cholerae encoding a putative multisubunit $\mathrm{Na}^{+} / \mathrm{H}^{+}$antiporter was cloned and functionally expressed in the antiporter-deficient strain of Escherichia coli EP432. Cells of EP432 expressing Vc-Mrp exhibited resistance to $\mathrm{Na}^{+}$and $\mathrm{Li}^{+}$as well as to natural bile salts such as sodium cholate and taurocholate. When assayed in everted membrane vesicles of the E. coli EP432 host, Vc-Mrp had sufficiently high antiport activity to facilitate the first extensive analysis of Mrp system from a Gram-negative bacterium encoded by a group 2 mrp operon. Vc-Mrp was found to exchange protons for $\mathrm{Li}^{+}, \mathrm{Na}^{+}$, and $\mathrm{K}^{+}$ions in $\mathrm{pH}$-dependent manner with maximal activity at $\mathrm{pH}$ 9.0-9.5. Exchange was electrogenic (more than one $\mathrm{H}^{+}$translocated per cation moved in opposite direction). The apparent $\mathrm{K}_{\mathrm{m}}$ at $\mathrm{pH} 9.0$ was $1.08,1.30$, and $68.5 \mathrm{mM}$ for $\mathrm{Li}^{+}, \mathrm{Na}^{+}$, and $\mathrm{K}^{+}$, respectively. Kinetic analyses suggested that Vc-Mrp operates in a binding exchange mode with all cations and protons competing for binding to the antiporter. The robust ion antiport activity of Vc-Mrp in sub-bacterial vesicles and its effect on bile resistance of the
\end{abstract}

heterologous host make Vc-Mrp an attractive experimental model for the further studies of biochemistry and physiology of Mrp systems.

Copyright $\odot 2008$ S. Karger AG, Basel

\section{Introduction}

Bacterial $m r p$ loci encode a phylogenetically distinct group of highly unusual multisubunit cation/proton antiporters (Mrp systems) which exchange cytoplasmic $\mathrm{Na}^{+}, \mathrm{Li}^{+}$and/or $\mathrm{K}^{+}$ions for extracellular $\mathrm{H}^{+}$. Mrp systems are widespread among bacteria and archaea and comprise a separate CPA3 (proton antiporter-3) class of the transporter classification system [Saier et al., 1999]. Other names suggested by independent groups to designate operons homologous to mrp are: pha (for $\mathrm{pH}$ adaptation) in Sinorhizobium meliloti [Putnoky et al., 1998], mnh (for multisubunit $\mathrm{Na}^{+} / \mathrm{H}^{+}$antiporter) in Staphylococcus aureus [Hiramatsu et al., 1998], sha (for sodium-hydrogen antiporter) in Bacillus [Kosono et al., 2000]. Here, we will use Mrp (for multiple resistance and $\mathrm{pH}$-related antiporter) to designate all of them. Mrp systems are a relatively recent discovery. Available physiological and genetic data on Mrp systems leave major questions about

\section{KARGER}

Fax +4161306 1234

E-Mail karger@karger.ch

www.karger.com
(C) 2008 S. Karger AG, Basel

Accessible online at: www.karger.com $/ \mathrm{mmb}$
Pavel Dibrov

Department of Microbiology, University of Manitoba, Fort Garry Campus Rm. 425 Buller Bldg

Winnipeg, Man. R3T 2N2 (Canada)

Tel. +1 204474 8059, Fax +1 204474 7603, E-Mail dibrovp@ms.umanitoba.ca 
this unusual transporter group, as summarized in a recent review [Swartz et al., 2005a].

Mrp systems are proposed to be uniquely complex multi-subunit monovalent cation/proton antiporters [Hiramatsu et al., 1998; Swartz et al., 2005a]. Very recently, complex formation by the mrpABCDEFG gene products was demonstrated experimentally in Bacillus subtilis [Kajiyama et al., 2007]. There are two major types of $m r p$ operons, among which there are species-specific variations [see Swartz et al., 2005a, and references therein]: group 1 with gene order $m r p A B C D E F G$ (e.g., in bacilli, staphylococci, sinorhizobia) and group 2 with gene order $m r p A^{\prime}$ $C D E F G$ (e.g., in corynebacteria and pseudomonadae). A group 2 operon that encodes the Mrp system of Vibrio cholerae (Vc-Mrp) is the subject of this study and is the only Mrp system found among sequenced Vibrio strains [Swartz et al., 2005a]. In group 2 operons, the first two genes of the operon are fused yielding $m r p A^{\prime}$, an extended variant of $m r p A$ with an additional $m r p B$ domain [Swartz et al., 2005a]. In turn, $m r p A$ is possibly a result of an earlier fusion of $m r p D$ and $m r p B$, so that either type of operon contains two copies of $m r p B$ coding region [Swartz et al., 2005a]. Deletion analyses of the S. aureus [Hiramatsu et al., 1998] and B. subtilis [Ito et al., 2000] operons demonstrated that all the mrp gene products are required for the maximal Mrp-associated $\mathrm{Na}^{+}$resistance. These findings indicate that the Mrp antiporters probably function as hetero-oligomeric complexes, in contrast to most other prokaryotic secondary monovalent cation/proton exchangers which are single membrane polypeptides or homo-oligomers [Gerchman et al., 2001; Safferling et al., 2003].

Experiments with whole cells and sub-bacterial vesicles conducted by independent groups showed that the Mrp systems from various sources differ in their specificity toward monovalent cations. In alkaliphilic bacilli [Hamamoto et al., 1994; Ito et al., 2000; Swartz et al., 2007] and in S. aureus [Hiramatsu et al., 1998; Swartz et al., 2007] the Mrp system functions as a $\mathrm{Na}^{+}\left(\mathrm{Li}^{+}\right) / \mathrm{H}^{+}$antiporter. In B. subtilis the possibility of Mrp catalyzing both $\mathrm{Na}^{+} / \mathrm{H}^{+}$and $\mathrm{K}^{+} / \mathrm{H}^{+}$exchange was raised by physiological studies [Ito et al., 1999], but recent data indicate that $B$. subtilis Mrp only catalyzes $\mathrm{Na}^{+}\left(\mathrm{Li}^{+}\right) / \mathrm{H}^{+}$antiport [Swartz et al., 2007]. On the other hand, S. meliloti Mrp (Pha1) apparently acts as a specific $\mathrm{K}^{+} / \mathrm{H}^{+}$antiporter [Putnoky et al., 1998]. In all studied cases, however, the Mrp systems operate as typical secondary ion exchangers, being energized by the protonmotive force $(\Delta \mathrm{p})$. Bacillus Mrp antiporters can apparently use the transmembrane electric potential, $\Delta \psi$, as a sole driving force for $\mathrm{Na}^{+}$translocation [Hamamoto et al., 1994; Ito et al., 1999, 2000; Swartz et al., 2007], which indicates an electrogenic antiport with the stoichiometry $\mathrm{H}^{+}: \mathrm{Na}^{+}>1$. Sequence similarities between several Mrp proteins and subunits of NADH:quinone oxidoreductases [see Swartz et al., 2005a and cited references] prompted the hypothesis of possible additional primary energization mode of Mrp [Bayer et al., 2006; Ito et al., 2001]. This hypothesis posited that Mrp systems could directly use the energy of a redox reaction for the energization of monovalent cation/proton antiport. However, direct experimental examination did not support this possibility [Ito et al., 2001; Swartz et al., 2005b].

The monovalent cation/proton antiport activity of Mrp systems has important physiological roles in alkali, $\mathrm{Na}^{+}$, and $\mathrm{K}^{+}$resistance [Hamamoto et al., 1994; Ito et al., 1999; Kosono et al., 1999; Putnoky et al., 1998] with significant impact on sporulation [Kosono et al., 2000] and symbiotic nitrogen fixation [Putnoky et al., 1998]. Recent analysis of deletion mutant revealed an important role of Mrp in the pathogenesis of Pseudomonas aeruginosa [Kosono et al., 2005]. There is another important activity also associated with Mrp, namely its capacity for cholate efflux, documented in B. subtilis [Ito et al., 1999, 2000]. It is not yet clear how the Mrp-mediated cholate transport is related to $\mathrm{Na}^{+}$flux through Mrp. Deletion analysis suggests that MrpF, which shows a sequence similarity to $\mathrm{Na}^{+}$-coupled bile transporters, may be responsible for cholate transport by itself [Ito et al., 2000]. However, the initial assays of MrpF-dependent cholate and $\mathrm{Na}^{+}$efflux have not shown coupling between these two substrates [Ito et al., 2000].

Detailed biochemical analysis of Mrp antiporters is impeded by the fact that the signals in standard fluorescence-based assays are typically very weak [Hiramatsu et al., 1998; Ito et al., 2001]. In this study, the group $2 \mathrm{Mrp}$ system from $V$. cholerae, Vc-Mrp, has been overexpressed in its functional form in the $\mathrm{Na}^{+} / \mathrm{H}^{+}$antiport-deficient strain of E. coli, EP432 [Pinner et al., 1993]. The robust antiport activity observed in assays of everted membrane vesicles from this transformant made it possible, for the first time, to measure key kinetic parameters of Vc-Mrp and to probe its stoichiometry. Of note, Vc-Mrp showed the ability to transport $\mathrm{K}^{+}$as well as $\mathrm{Na}^{+}$and $\mathrm{Li}^{+}$. In addition, it enhanced the resistance of the heterologous host strain to natural bile salts. The latter property had only been shown previously for the B. subtilis Mrp system belonging to the group 1 of $m r p$ operons, and which conferred resistance to cholate [Ito et al., 1999, 2000]. All these features make Vc-Mrp a very attractive experimental model for the further studies of biochemistry and physiology of Mrp systems.

J Mol Microbiol Biotechnol 2009;16:176-186 
Fig. 1. Structure of the mrp operon in $V$. cholerae. Shown are the genes comprising the operon, their length, names of corresponding loci (according to the TIGR database,//www.tigr.org/tigr-scripts/CMR2/ GenomeTabs.spl?database $=$ gvc\#4), together with calculated length and molecular mass of putative products, as well as the number of putative transmembrane segments (TMS) for each protein.

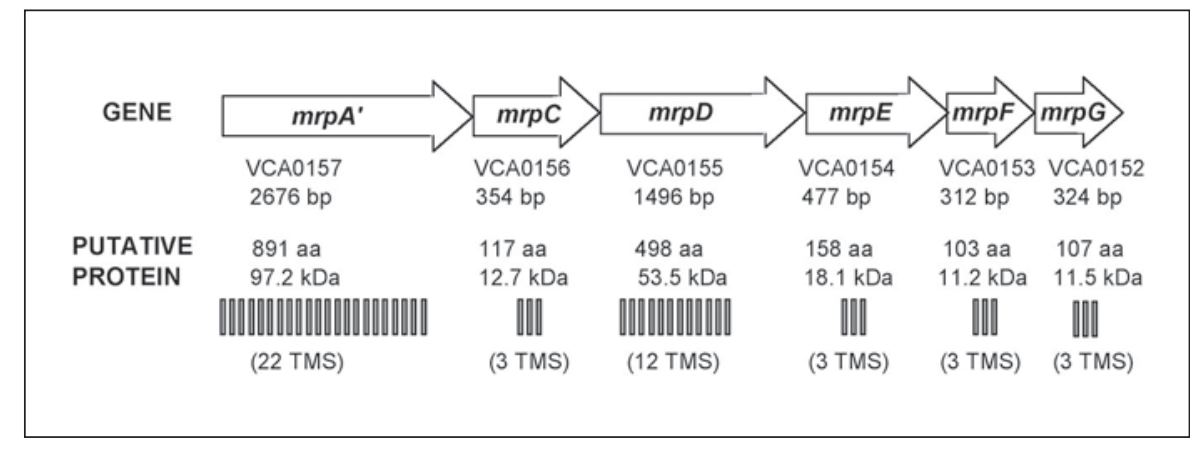

\section{Results}

Functional Expression of Vc-mrp Operon in E. coli EP432

The entire Vc-mrp operon containing the genes from $m r p A$ ' to $m r p G$ of $V$. cholerae (fig. 1) was cloned under the control of the arabinose-inducible $\mathrm{P}_{\mathrm{BAD}}$ promoter, and introduced into $\mathrm{Na}^{+} / \mathrm{H}^{+}$antiport-deficient E. coli EP432. Sequence analyses of the cloned operon revealed several nucleotide substitutions compared to the sequence of the genomic mrp published at http://www.tigr.org for V. cholerae biotype $\mathrm{El}$ Tor resulting in a few deviations at the amino acid level, namely, seven following substitutions were found: in Vc-MrpA', I12T (ATC $\rightarrow$ ACC), V657M $($ GTG $\rightarrow$ ATG), P669A (CCG $\rightarrow$ GCG), and V739I (GTC $\rightarrow$ ATC); in Vc-MrpD, P105L (CCC $\rightarrow$ CTC) and Q439P $(\mathrm{CAA} \rightarrow \mathrm{CCG}$ ); in Vc-MrpE, I68V (ATC $\rightarrow$ GTC). Independent sequencing of the chromosomal DNA of O395N1 strain amplified by PCR with the above primers yielded a sequence identical to that of pVcMrp insert. Therefore, all the substitutions reflect the actual difference between genomes of classical strain of $V$. cholerae used in this study and published El Tor biotype. Interestingly, all these substitutions are rather conservative (neutral residue substituted by another neutral residue, or neutral residue substituted by uncharged polar one and vice versa). The Vc-mrp sequence from the O395-N1 strain was deposited in GenBank under the accession No. EF546428.

EP432 strain of E. coli is hypersensitive to environmental $\mathrm{Na}^{+}$and $\mathrm{Li}^{+}$due to its inability to maintain low cytoplasmic concentration of these cations caused by the deletion of two $\mathrm{Na}^{+} / \mathrm{H}^{+}$antiporters, NhaA and $\mathrm{NhaB}$ [Harel-Bronstein et al., 1995; Padan et al., 2001; Pinner et al., 1993]. When grown in the presence of $0.5 \mathrm{mM}$ arabinose, the EP432 transformant in which Vc-mrp was expressed showed enhanced resistance toward $\mathrm{Na}^{+}$and $\mathrm{Li}^{+}$ ions (fig. 2), thus indicating that Vc-Mrp is functional in the heterologous host. Protection against added alkali cations conferred by mrp expression was $\mathrm{pH}$-dependent with a maximum in alkaline ( $\mathrm{pH} 8.5)$ medium, which was especially evident with $\mathrm{Li}^{+}$(fig. 2). This $\mathrm{pH}$ profile indicates that the alkali cation extrusion via Vc-Mrp can be energized by the transmembrane electric potential difference, $\Delta \psi$, because the $\Delta \mathrm{pH}$ component of the total driving force would be zero or even reversed (i.e. more acid inside than outside the cells) at an external $\mathrm{pH}$ of 8.5.

Since the Mrp system of $B$. subtilis has been implicated in cholate transport [Ito et al., 1999, 2000], resistance of EP432/pVcMrp cells to cholate was examined at different $\mathrm{pH}$ values. As shown in figure $3 \mathrm{a}, \mathrm{Vc}-\mathrm{Mrp}$ rendered transformants resistant to $7.5-22.5 \mathrm{~mm}$ sodium cholate, but only at pH 7.2 in contrast to the protection from alkali cations (fig. 2). Microscopic observation revealed that used concentrations of bile salts did not affect the shape of cells thus excluding possible artifacts of measurements of growth by registering the optical density at $600 \mathrm{~nm}$. The observed difference in $\mathrm{pH}$ dependence suggests the possibility that the Vc-Mrp-mediated transport of alkali cations and transport of cholate may be in fact two independent activities of the same transport system. Such a suggestion is in accord with previous failure to demonstrate linkage between Mrp-dependent transport of $\mathrm{Na}^{+}$ and cholate in bacilli [Ito et al., 2000].

Further, Vc-Mrp was found to protect EP432 transformants from conjugated bile salt, sodium taurocholate, a compound naturally occurring in bile (fig. 3b). Of note, in this case Vc-Mrp offers no protection until the concentration of added taurocholate exceeds $22.5 \mathrm{mM}$ (fig. 3b). The growth yields of both transformants at $22.5 \mathrm{mM}$ taurocholate is nearly threefold lower than that in the absence of added taurocholate (fig. $3 \mathrm{~b}$ ), but as the taurocholate concentration was raised to the range of $22.5-42.5 \mathrm{mM}$, Vc-Mrp-dependent protection was evident by the better 
Fig. 2. Vc-Mrp protects E. coli EP432 cells against sodium and lithium ions. Cells were transformed with either pVcMrp (closed symbols) or 'empty' pBAD24 (open symbols) and grown aerobically as described in 'Experimental Procedures' in the presence of $0.5 \% \mathrm{~L}$-arabinose and indicated concentrations of $\mathrm{NaCl}$ or $\mathrm{LiCl}$ for $18 \mathrm{~h}$. The growth yield was measured as optical density at $600 \mathrm{~nm}\left(\mathrm{OD}_{600}\right)$. Starting $\mathrm{OD}_{600}$ in all cases was approximately 0.05 . Plotted are averages of at least four independent experiments. Bars show standard deviation.
Fig. 3. Vc-Mrp confers resistance to cholate in E. coli EP432 transformants. Cells were transformed with either pVcMrp (closed symbols) or 'empty' pBAD24 (open symbols) and grown aerobically as described in 'Experimental Procedures' in the presence of $0.5 \%$ arabinose and varying concentrations of sodium cholate for $16 \mathrm{~h}$. The growth yield was measured as optical density at $600 \mathrm{~nm}\left(\mathrm{OD}_{600}\right)$. The $\mathrm{OD}_{600}$ at the start of the experiments was approximately 0.05 in all cases. Plotted are averages of at least four independent experiments. Bars show standard deviation.
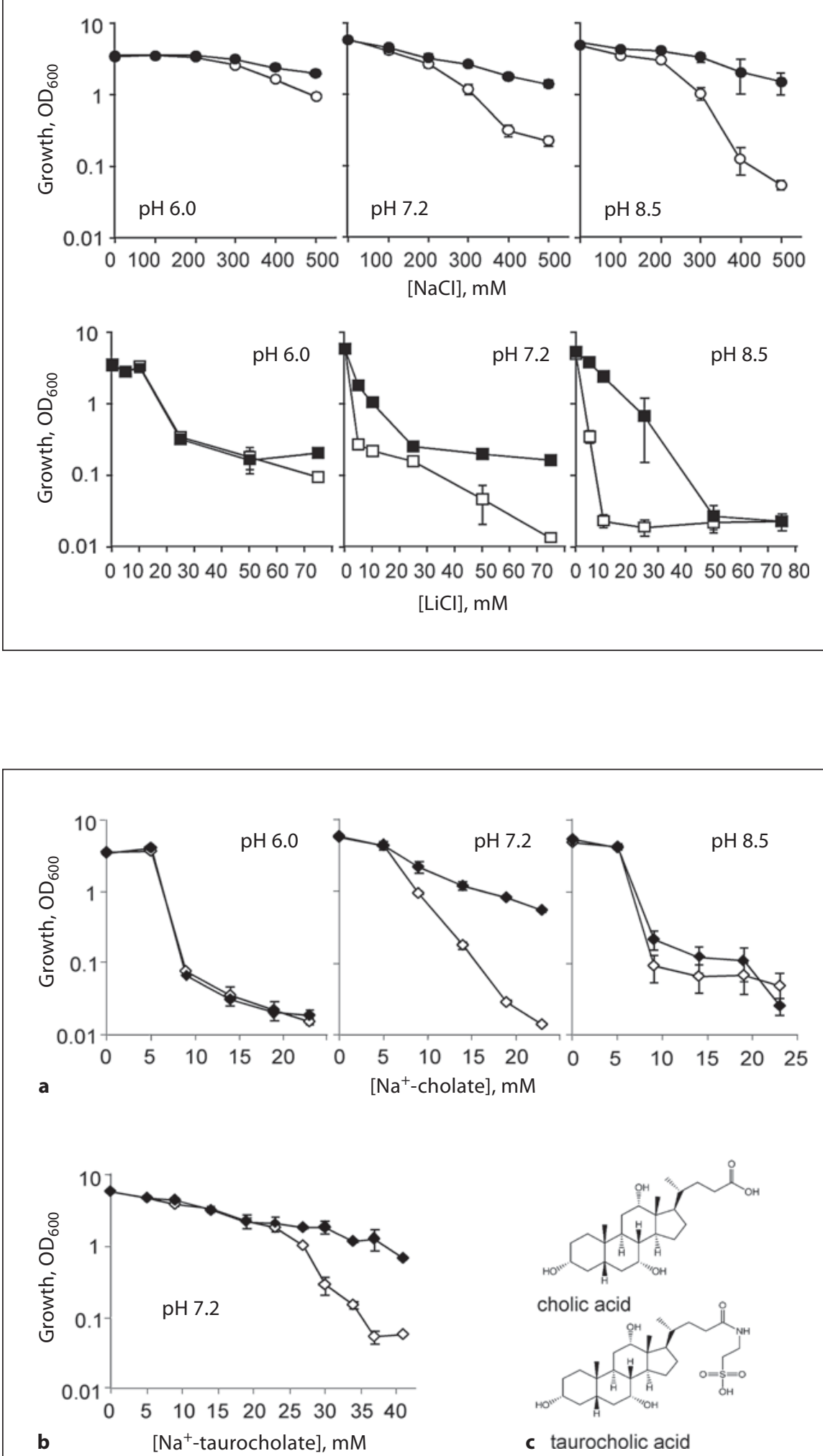

c taurocholic acid 

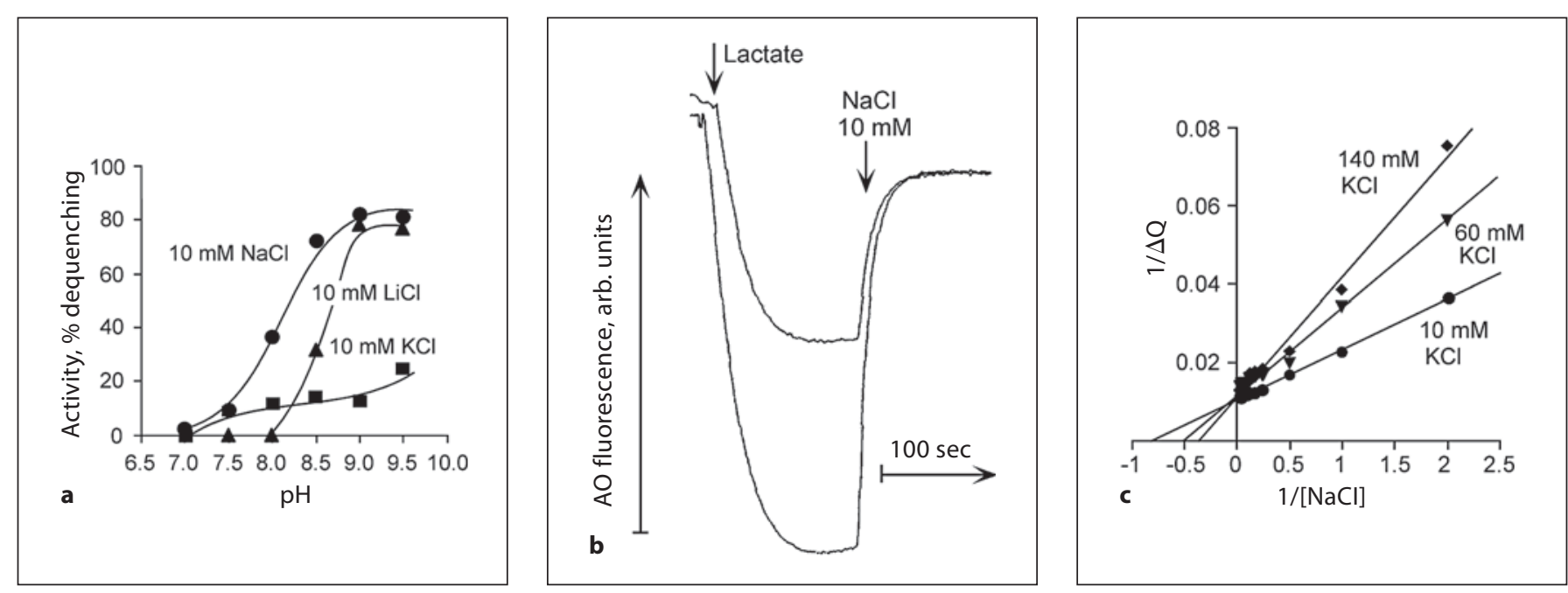

Fig. 4. Activity of Vc-Mrp in everted membrane vesicles. a pH profiles of antiport activities mediated by Vc-Mrp. Everted membrane vesicles were isolated from EP432 cells transformed with pVcMrp or 'empty' pBAD24 and assayed with $10 \mathrm{mM}$ of specified salt at various $\mathrm{pH}$ values as described in 'Experimental Procedures'. In each case, residual nonspecific activity measured in 'empty' vesicles was subtracted from that registered in Vc-Mrpcontaining vesicles and the resulting Vc-Mrp-dependent activity was plotted as a function of $\mathrm{pH}$. Experiments were repeated 3 times for each cation and gave nearly identical results. b High concentrations of external $\mathrm{KCl}$ do not prevent $\mathrm{Na}^{+} / \mathrm{H}^{+}$antiport mediated by Vc-Mrp. Vesicles were assayed with $10 \mathrm{~mm} \mathrm{NaCl}$ at $\mathrm{pH} 9.0$ in the standard choline chloride experimental medium supplemented with $140 \mathrm{mM} \mathrm{KCl}$ (upper trace) or the same medium containing $280 \mathrm{mM}$ of choline-Cl instead of $140 \mathrm{~mm}$ (lower trace) to compensate the difference in osmolarity. Representative data of three independent experiments are shown. $\mathbf{c} \mathrm{K}^{+}$ions compete with $\mathrm{Na}^{+}$for the antiporter. Dequenching of $\mathrm{AO}$ fluorescence $(\Delta \mathrm{Q})$ in response to the addition of varying $[\mathrm{NaCl}]$ was registered at $\mathrm{pH} 9.0$ in the standard choline chloride medium supplemented with indicated concentrations of $\mathrm{KCl}$. Concentrations of choline$\mathrm{Cl}$ were varied accordingly to keep the osmolarity constant. Data were plotted in reciprocal coordinates. Obtained apparent $\mathrm{K}_{\mathrm{m}}$ values for $\mathrm{Na}^{+}$are: $1.3 \mathrm{mM}$ (at $\left.10 \mathrm{mM} \mathrm{KCl}\right), 1.9 \mathrm{mM}$ (at $60 \mathrm{mM} \mathrm{KCl}$ ), and $2.8 \mathrm{mM}$ (at $140 \mathrm{mM} \mathrm{KCl}$ ). growth of Vc-Mrp transformant (fig. 3b). While these data per se do not prove the bile efflux via Vc-Mrp, they are consistent with the notion that Vc-Mrp-dependent protection from bile salts may be achieved by active extrusion via Vc-Mrp, with cholate being a preferable substrate. If so, the additional amidosulfonate group of taurocholate (fig. 3c) could rise the $\mathrm{K}_{\mathrm{m}}$ of Vc-Mrp for this bulkier compound. Direct assays of bile salt transport will be needed to examine the role of Vc-Mrp in bile resistance.

Phenotypes of the EP432/pVcMrp transformants described above clearly showed that the arabinose-induced expression of the Vc-Mrp system in E. coli resulted in the proper targeting/insertion of Vc-Mrp into the membrane, which preserved its ability to function as a cation/proton antiporter, allowing more detailed characterization of Vc-Mrp antiport in a subcellular experimental model.

\section{Cation-Proton Antiport Catalyzed by Vc-Mrp in \\ Everted Membrane Vesicles}

Measurements of Vc-Mrp-mediated cation-proton antiport in inside-out membrane vesicles isolated from
EP432/pVcMrp revealed that both $\mathrm{Na}^{+}$and $\mathrm{Li}^{+}$ions are good substrates for Vc-Mrp (fig. 4a, closed circles and triangles). In both cases, maximal activity was detected at alkaline $\mathrm{pH}$ of the experimental mixture. The $\mathrm{pH}$ profile for $\mathrm{Li}^{+} / \mathrm{H}^{+}$exchange was shifted toward more alkaline $\mathrm{pH}$ by one $\mathrm{pH}$ unit relative to $\mathrm{Na}^{+} / \mathrm{H}^{+}$antiport. At $\mathrm{pH} 8.0$, $\mathrm{Na}^{+} / \mathrm{H}^{+}$antiport reached its half-maximal magnitude while $\mathrm{Li}^{+} / \mathrm{H}^{+}$antiport was not detectable at $\mathrm{pH}<8.5$ (fig. 4a). Vc-Mrp also catalyzed measurable $\mathrm{K}^{+} / \mathrm{H}^{+}$antiport with the magnitude steadily increasing from $\mathrm{pH} 7.5$ to $\mathrm{pH} 9.5$ (fig. 4 a, closed squares). For this set of experiments, the vesicles were isolated and assayed in $\mathrm{K}^{+}$-free buffer. Under these conditions, a small background cation-proton antiport activity (i.e. small dequenching) was observed in assays of control 'empty' vesicles isolated from parental EP432 strain (not shown). This background activity never exceeded $18 \%$ of $\mathrm{AO}$ dequenching and was completely eliminated by introduction of $10 \mathrm{mM} \mathrm{K}^{+}$into experimental solutions. The background was measured at every $\mathrm{pH}$ examined for each cation in separate control experiments and subtracted from the levels obtained in 
Vc-Mrp-containing vesicles to yield data sets plotted in figure $4 \mathrm{a}$. The alkaline $\mathrm{pH}$ optimum for Vc-Mrp-mediated antiport with each of its cation substrates is consistent with observations on other Mrp systems, with Mrp roles in $\mathrm{pH}$ homeostasis, and with the greater sensitivity of bacteria to the cytotoxic effects of $\mathrm{Na}^{+}$at alkaline $\mathrm{pH}$ [Swartz et al., 2005a, 2007]. Even if antiport is energized by a $\Delta \psi$ as indicated by experiments below, proton capture from the outside is increasingly difficult as the external $\mathrm{pH}$ rises. One proposed rationale for a Mrp complex is the presentation of a large protein surface that might facilitate proton gathering in support of antiport at high pH [Swartz et al., 2005a].

The lower levels of $\mathrm{K}^{+} / \mathrm{H}^{+}$antiport than $\mathrm{Na}^{+}\left(\mathrm{Li}^{+}\right) / \mathrm{H}^{+}$ antiport mediated by Vc-Mrp suggest that the latter activity is the major physiological mode of Vc-Mrp. In support of this suggestion, addition of $140 \mathrm{mM} \mathrm{KCl}$ into the assay buffer did not prevent the $\Delta \mathrm{pH}$ response on addition of $10 \mathrm{mM} \mathrm{NaCl}$ to Vc-Mrp-containing vesicles at $\mathrm{pH}$ 9.0 (fig. $4 \mathrm{~b}$, upper trace). The lower magnitude of the respiration-induced $\Delta \mathrm{pH}$ in $\mathrm{K}^{+}$-rich buffer is to be expected since respiration would be occurring concurrently with Vc-Mrp-mediated $\mathrm{K}^{+} / \mathrm{H}^{+}$exchange during energization, resulting in a lower steady-state quench (fig. $4 \mathrm{~b}$, compare upper and lower traces). Lowered percent of dequenching upon addition of $\mathrm{Na}^{+}$in $\mathrm{K}^{+}$-rich buffer indicated possible competition between $\mathrm{Na}^{+}$and $\mathrm{K}^{+}$. This possibility was further analyzed in the next series of experiments, as described in the next section.

\section{Kinetic Behavior of Vc-Mrp Is Consistent with Binding} Exchange Mechanism

Since the $\mathrm{pH}$ profile of $\mathrm{K}^{+} / \mathrm{H}^{+}$exchange mediated by Vc-Mrp differs significantly from that of $\mathrm{Na}^{+} / \mathrm{H}^{+}$and $\mathrm{Li}^{+} /$ $\mathrm{H}^{+}$exchange, $\mathrm{Na}^{+} / \mathrm{H}^{+}$antiport at $\mathrm{pH} 9.0$ was next measured in the presence of three different concentrations of $\mathrm{KCl}$ added to the experimental medium. These competition assays clearly demonstrated that $\mathrm{K}^{+}$ions compete with $\mathrm{Na}^{+}$for the antiporter, affecting its apparent $\mathrm{K}_{\mathrm{m}}$ for $\mathrm{Na}^{+}$(fig. 4c). Therefore, all three transported cations appear to share the same intramolecular translocation pathway and observed low overall $\mathrm{K}^{+} / \mathrm{H}^{+}$exchange through Vc-Mrp (fig. 4a) probably reflects a lower affinity of $\mathrm{Vc}-\mathrm{Mrp}$ for $\mathrm{K}^{+}$ions. The apparent $\mathrm{K}_{\mathrm{m}}$ values for $\mathrm{Vc}$ Mrp with each of the three substrate cations were determined as the cation concentration required for a halfmaximal $\mathrm{AO}$ dequenching at the optimal $\mathrm{pH}$ of 9.0. The antiporter exhibited an apparent $\mathrm{K}_{\mathrm{m}}$ for $\mathrm{Na}^{+}$or $\mathrm{Li}^{+}$close to $1.0 \mathrm{~mm}$ (fig. 5). Such low $\mathrm{K}_{\mathrm{m}}$ values are typical for many bacterial $\mathrm{Na}^{+} / \mathrm{H}^{+}$antiporters, including $\mathrm{Vc}-\mathrm{NhaD}$ [Dzio- ba et al., 2002; Habibian et al., 2005; Ostroumov et al., 2002] and Ec-NhaA [Dibrov and Taglicht, 1993; Tzubery et al., 2004]. Even in the presence of $140 \mathrm{mM} \mathrm{KCl}, \mathrm{K}_{\mathrm{m}}$ for $\mathrm{Na}^{+}$was $2.8 \mathrm{mM}$ (fig. 4c). Since bacteria usually maintain high levels of cytoplasmic potassium, this $\mathrm{K}_{\mathrm{m}}$ value may be closer to the in vivo situation. In contrast, the $\mathrm{K}_{\mathrm{m}}$ for Vc-Mrp with $\mathrm{K}^{+}$is $68.5 \mathrm{~mm}$, higher by almost two orders of magnitude (fig. 5).

Although the $\mathrm{Na}^{+}$-dependent $\mathrm{H}^{+}$export from everted vesicles via Vc-Mrp was not prevented by the addition of external $\mathrm{K}^{+}$(fig. $4 \mathrm{~b}, \mathrm{c}$ ), intravesicular $\mathrm{K}^{+}$arrested it completely unless the $\mathrm{K}^{+}$ionophore valinomycin was added (fig. 6a). The only difference between this experiment and the one shown in figure $4 \mathrm{~b}$ is that here $140 \mathrm{mM} \mathrm{K}_{2} \mathrm{SO}_{4}$ is present outside and inside the vesicles. This observation indicates that $\mathrm{K}^{+}$and $\mathrm{H}^{+}$compete for the binding to the antiporter. One could argue that, alternatively, valinomycin may boost the proton gradient as a driving force for $\mathrm{Na}^{+}$transport in $\mathrm{K}^{+}$-rich buffer. However, this does not explain the total arrest of the $\mathrm{Na}^{+}$-dependent $\mathrm{H}^{+}$movement by high internal $\mathrm{K}^{+}$in the absence of valinomycin shown in figure $6 \mathrm{a}$. Such arrest does not happen when high $\left[\mathrm{K}^{+}\right]$is present only in external medium (fig. $4 \mathrm{~b}$ ). Therefore the most plausible explanation is that the flux of $\mathrm{H}^{+}$from the intravesicular space is inhibited by the high internal $\left[\mathrm{K}^{+}\right]$. The addition of valinomycin dissipates $\Delta \psi$ on the membrane (fig. $6 \mathrm{~b}$, the last addition), thus converting it into $\Delta \mathrm{pH}$ (more acidic inside the vesicles). This increases internal $\left[\mathrm{H}^{+}\right]$so that now protons compete favorably with $\mathrm{K}^{+}$in and the $\mathrm{Na}^{+}\left(\mathrm{Li}^{+}\right) / \mathrm{H}^{+}$antiport can proceed upon the addition of external cation, albeit at a considerably slower rate (compare the lower trace in fig. 6 a to that in fig. $4 \mathrm{~b}$ ).

Parallel measurements of $\Delta \psi$ showed that the addition of $\mathrm{Li}^{+}$(as shown in fig. 6b) or $\mathrm{Na}^{+}$(not shown) did not perturb the membrane potential. These data, together with the results of competition experiments shown in figure $4 \mathrm{c}$, indicate that all transported cations, including protons, compete for the antiporter operating in the binding exchange mode, as suggested for other antiporters [Huang et al., 2003; Hunte et al., 2005] and illustrated by the model diagrammed in figure $6 \mathrm{c}$. Here, $\mathrm{C}_{\mathrm{o}}$ and $\mathrm{C}_{\mathrm{i}}$ denote two unloaded forms of Vc-Mrp with its cation-binding site accessible to ions from the outer or inner side of the membrane, respectively. At any time, the cation-binding site may be empty or occupied by either $1 \mathrm{~K}^{+}$ion, or 1 $\mathrm{Na}^{+}\left(\mathrm{Li}^{+}\right)$ion, or by $n$ protons. Only $\mathrm{Na}^{+}$-loaded but not $\mathrm{Li}^{+}$-loaded forms of antiporter are shown for simplicity. When internal $\left[\mathrm{K}^{+}\right]$is low, the catalytic cycle includes partial steps $1 \rightarrow 2 \rightarrow 3 \rightarrow 4 \rightarrow 5 \rightarrow 6$ (in the case of 

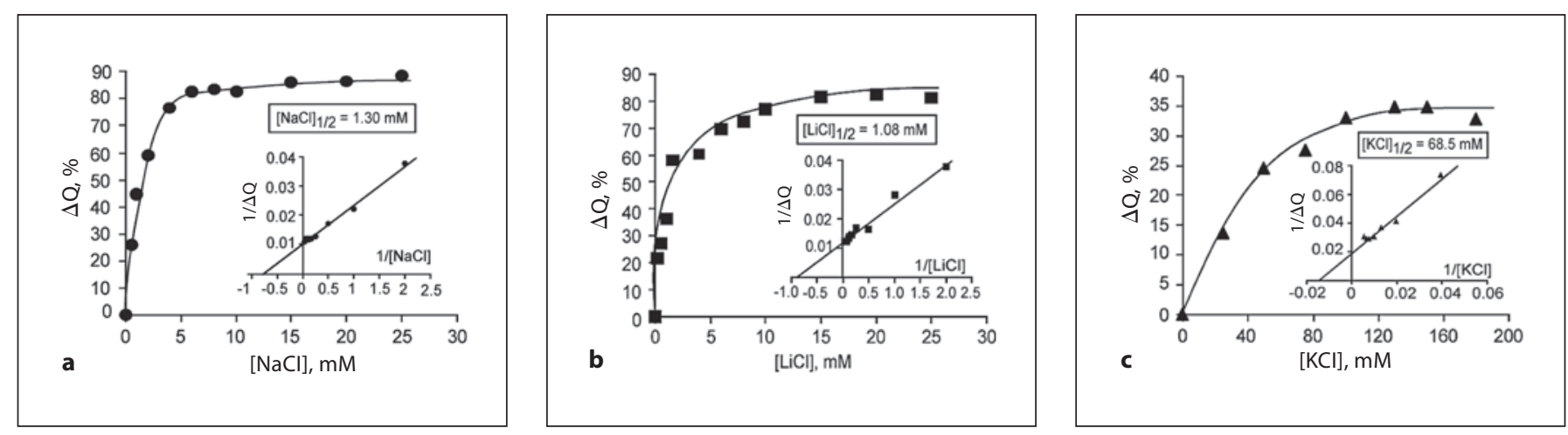

Fig. 5. Determination of kinetic parameters of Vc-Mrp in everted membrane vesicles isolated from EP432 transformant cells. Assays were performed at $\mathrm{pH} 9.0$ with varying concentrations of
$\mathrm{NaCl}$ (circles, a), $\mathrm{LiCl}$ (squares, b), or $\mathrm{KCl}$ (triangles, c) as described in 'Experimental Procedures'. $\Delta \mathrm{Q}=$ Percent of dequenching of the $\mathrm{AO}$ fluorescence.

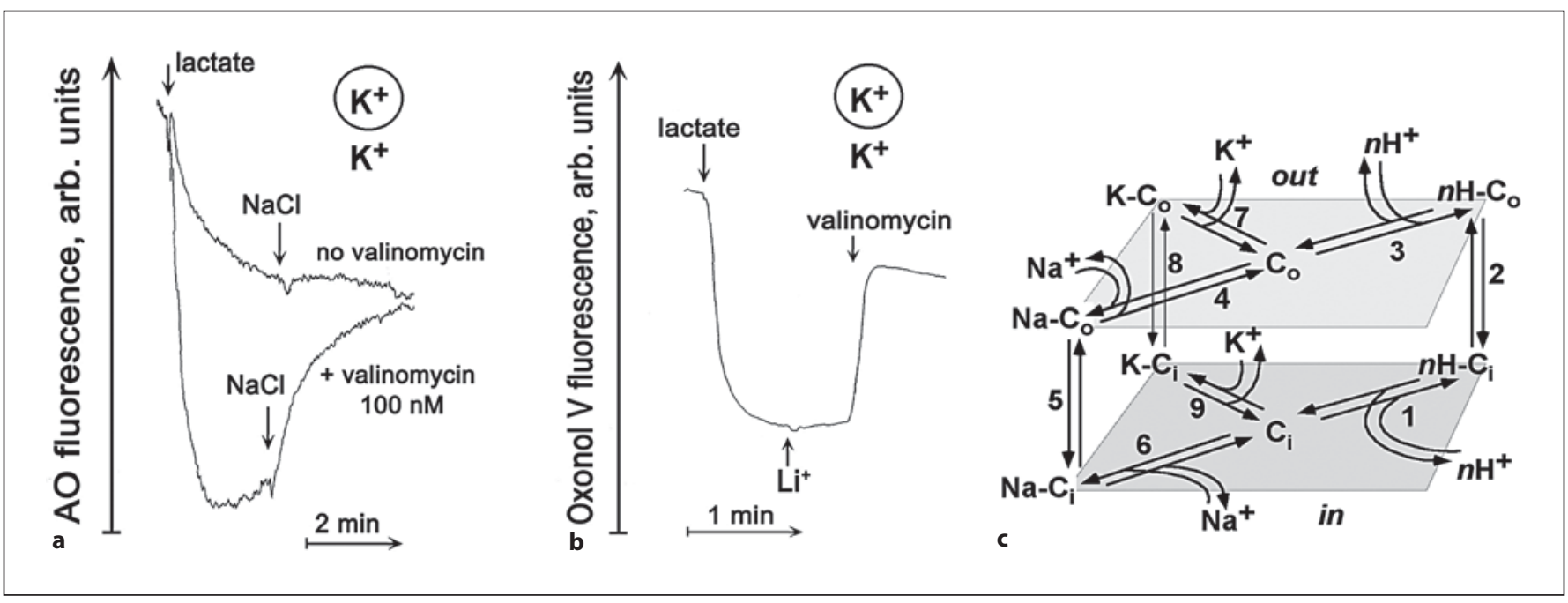

Fig. 6. Kinetic analysis of Vc-Mrp. a A high concentration of intravesicular $\mathrm{K}^{+}$prevents cation-proton exchange by Vc-Mrp. Vesicles were isolated from EP432/pVcMrp cells in a high potassium buffer and assayed in the same buffer at pH 9.0. $5 \mathrm{mM}$ Tris-D-lactate was used to energize respiration-dependent proton pumping, then $10 \mathrm{mM} \mathrm{NaCl}$ was added to initiate antiport in the absence (upper trace) or presence of $100 \mathrm{~nm}$ valinomycin (lower trace). b Addition of alkali cation ( $50 \mathrm{mM} \mathrm{LiCl})$ does not perturb the $\Delta \psi$ of the membrane of vesicles. Fluorescence of $\Delta \psi$-sensitive dye, oxonol V, was monitored instead of AO; all other conditions as in a. Representative of five independent experiments is shown. c Kinetic model of Vc-Mrp based on the binding exchange mechanism. See the text for discussion.
$\mathrm{Na}^{+}\left(\mathrm{Li}^{+}\right) / \mathrm{H}^{+}$antiport $)$or $1 \rightarrow 2 \rightarrow 3 \rightarrow 7 \rightarrow 8 \rightarrow 9\left(\mathrm{~K}^{+} / \mathrm{H}^{+}\right.$ antiport). Due to the competition between $\mathrm{K}^{+}$and $\mathrm{H}^{+}$, high $\left[\mathrm{K}^{+}\right]$inside prevents protons from binding (thus eliminating steps $1 \rightarrow 2 \rightarrow 3$ ), but external $\mathrm{Na}^{+}$is still able to bind to the antiporter, as it is evident from figure $4 \mathrm{~b}$, because of the difference in $\mathrm{K}_{\mathrm{m}}$ for $\mathrm{Na}^{+}$vs. $\mathrm{K}^{+}$(fig. 5). Therefore, under these conditions only homologous $\mathrm{K}^{+} / \mathrm{K}^{+}$exchange (route $7 \rightarrow 8 \rightarrow 9$ ) or heterologous
$\mathrm{K}^{+} / \mathrm{Na}^{+}\left(\mathrm{Li}^{+}\right)$exchange (route $4 \rightarrow 5 \rightarrow 6 \rightarrow 9 \rightarrow 8 \rightarrow 7$ ) are allowed. Not surprisingly, either of these activities is electroneutral (fig. 6b).

\section{Probing the Electrogenicity of Cation-Proton Antiport} via $V c-M r p$

The above kinetic analysis does not determine $n$, the number of protons exchanged per each alkali cation in a 
Fig. 7. Probing the stoichiometry of VcMrp. Vesicles were isolated and assayed for $\Delta \psi$ at $\mathrm{pH} 9.0$ in a sorbitol-based medium devoid of $\mathrm{K}^{+}$and $\mathrm{Cl}^{-}$as described in 'Experimental Procedures'. Diethanolamine at $15 \mathrm{~mm}$ was added to the experimental mixture 5 min prior the addition of Oxonol V. Due to the absence of $\mathrm{K}^{+}$in the system, protonophore CCCP was added at the end of each measurement instead of valinomycin for the control. All other conditions as in figure $6 \mathrm{~b}$. Representative traces of five independent experiments are shown.

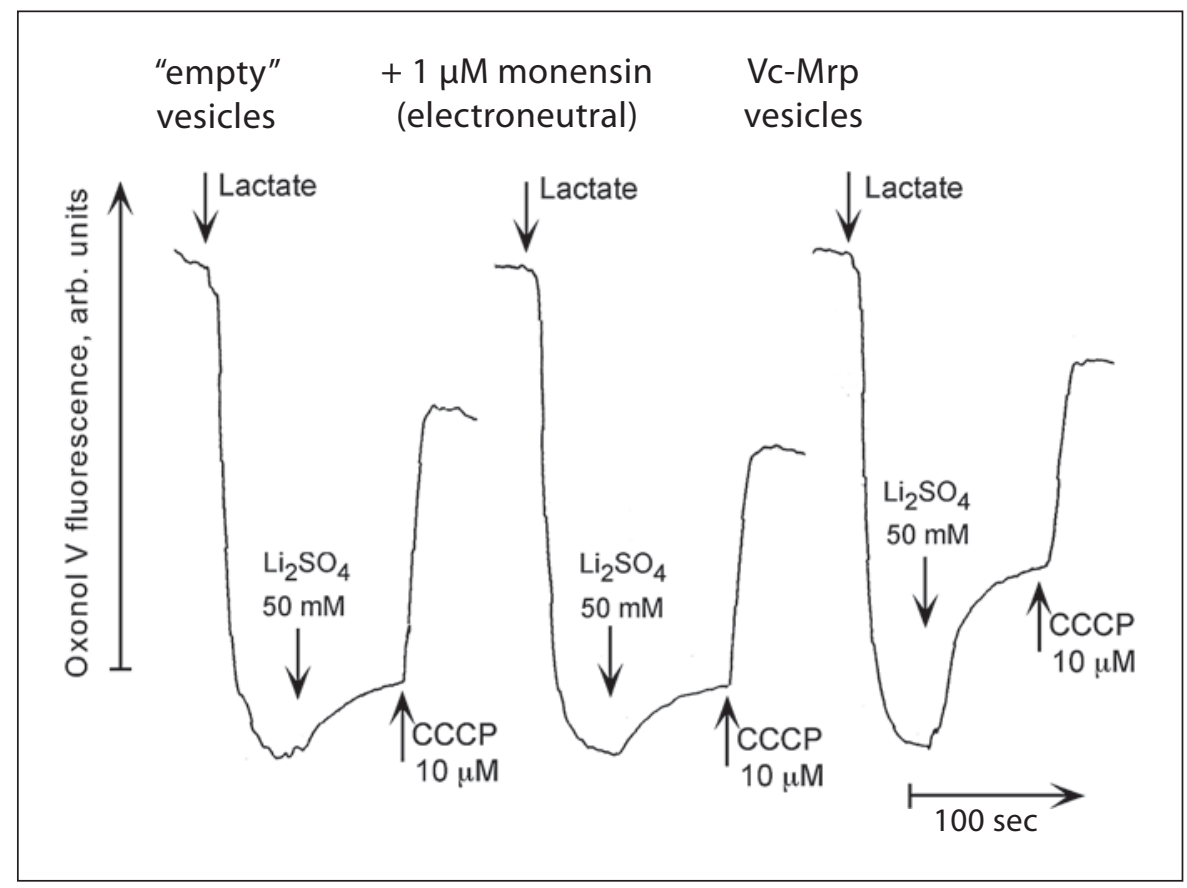

single turnover of the catalytic cycle of Vc-Mrp. Growth of EP432 transformants (fig. 2) indicates that Vc-Mrp might use $\Delta \psi$ to drive the export of alkali cations at high external $\mathrm{pH}$, implying that it catalyzes an electrogenic exchange of $1 \mathrm{Na}^{+}\left(\mathrm{Li}^{+}\right)$per $n \mathrm{H}^{+}(n>1.0)$. If so, the net transmembrane charge movement should result in (at least transient) dissipation of pre-established $\Delta \psi$ on the membrane upon addition of alkali cation.

In order to probe the electrogenicity of Vc-Mrp antiport, everted EP432 vesicles were isolated and assayed for $\Delta \psi$ in a sorbitol-based medium at $\mathrm{pH}$ 9.0. To maximize the respiration-generated $\Delta \psi, 15 \mathrm{~mm}$ diethanolamine was added to the vesicle suspension $5 \mathrm{~min}$ prior the addition of the $\Delta \psi$-sensitive dye oxonol V. For the control experiments, vesicles were isolated from the host EP432 cells transformed with the pBAD24 plasmid without $m r p$ insert ('empty' vesicles, left trace in fig. 7). Here, addition of lactate led to rapid generation of $\Delta \psi$ and the subsequent addition of $\mathrm{Li}^{+}$resulted in a slow, modest but reproducible depolarization, indicating the presence of electrogenic cation-transporting system(s) operating in the membrane of 'empty' vesicles. A similar modest background effect on $\Delta \mathrm{pH}$ was noted above. It is not clear at this time what transporters of the EP432 membrane may be responsible for this background activity, but a possible candidate is ChaA, a $\mathrm{K}^{+}\left(\mathrm{Ca}^{2+}\right)\left(\mathrm{Na}^{+}\right) / \mathrm{H}^{+}$antiporter that is active in alkaline media [Ivey et al., 1993; Ohyama et al., 1994; Radchenko et al., 2006].

Mrp Transport System in Vibrio cholerae
In another control, an artificial electroneutral $\mathrm{Na}^{+}\left(\mathrm{Li}^{+}\right) /$ $\mathrm{H}^{+}$exchanger, monensin, added at $1 \mu \mathrm{M}$ before lactate, did not affect this response (fig. 7, middle trace). On the other hand, in a separate control experiment the same concentration of monensin caused robust $\mathrm{Li}^{+}$-induced proton transfer in vesicles assayed for $\Delta \mathrm{pH}$ in standard choline- $\mathrm{Cl}$ medium (data not shown). Therefore the absence of effect of monensin on $\Delta \psi$ could not be attributed to the lack of its activity, but reflects the electroneutral exchange mediated by this compound. The addition of $\mathrm{Li}^{+}$to the Vc-Mrp-containing vesicles resulted in a partial dissipation of respiration-generated $\Delta \psi$. The dissipation was much faster and of significantly higher magnitude than that observed in both 'empty' and monensin controls (fig. 7, compare right trace with others). $\mathrm{Li}^{+}$was added to $50 \mathrm{mM}$ in the experiment shown in figure 7 because this concentration saturated the background activity observed in the two controls, but Vc-Mrp-dependent $\Delta \psi$ consumption was also observed when $\mathrm{Li}^{+}$was added at $5 \mathrm{mM}$ or when $\mathrm{Na}^{+}$or $\mathrm{K}^{+}$was used as substrate instead of $\mathrm{Li}^{+}$(data not shown). Again, monensin did not affect the background activity in the control vesicles at low concentrations of substrate cation added. These observations support an electrogenic character of the cation-proton antiport catalyzed by Vc-Mrp with the stoichiometry 1 $\mathrm{Li}^{+} / n \mathrm{H}^{+}(n>1.0)$. The approach exploited in this work is a qualitative one and does not allow for direct determination of $n$. Reconstitution of purified antiporter into pro-

J Mol Microbiol Biotechnol 2009;16:176-186 
teoliposomes is required for this task, as it was done earlier for Ec-NhaA [Taglicht et al., 1993] and Ec-NhaB [Pinner et al., 1994]. Although purification of a putative multi subunit transporter such as Vc-Mrp in its functional form poses a significant challenge, this is one of the most important future directions in studies on Mrp systems.

\section{Discussion}

This study provides the first detailed characterization of a 'group 2' Mrp system encoded by a six-gene operon with gene order $m r p A^{\prime} C D E F G$ (fig. 1). The results define Vc-Mrp as an electrogenic (exchanging more than one $\mathrm{H}^{+}$per each alkali cation) secondary cation-proton antiporter with broad cation specificity (fig. 4, 5). The ability of Vc-Mrp to use $\mathrm{K}^{+}$as a substrate (albeit with low affinity), in addition to $\mathrm{Na}^{+}$and $\mathrm{Li}^{+}$, differentiates it from recently characterized 'group 1' Mrp systems that act as more specific, high-affinity $\mathrm{Na}^{+}\left(\mathrm{Li}^{+}\right) / \mathrm{H}^{+}$antiporters [Swartz et al., 2007]. Vc-Mrp exhibits apparent $\mathrm{K}_{\mathrm{m}}$ values for $\mathrm{Na}^{+}$and $\mathrm{Li}^{+}$that are 1.1-1.3 mM (fig. 5), just a little higher than the submillimolar values displayed by 'group 1' Mrp systems that are among the lowest ever reported for bacterial $\mathrm{Na}^{+} / \mathrm{H}^{+}$antiporters [Swartz et al., 2007]. Like the group $1 \mathrm{Mrp}$ systems from S. aureus and Bacillus species [Swartz et al., 2007], Vc-Mrp exhibits an alkaline $\mathrm{pH}$ optimum; it is particularly notable that this optimum of $\mathrm{pH} 9.0-9.5$ is above the $\mathrm{pH}$ at which $V$. cholerae exhibits growth [Miller et al., 1984], as will be discussed below. Kinetic analyses in this study provide the first insights into the mechanism of cation exchange catalyzed by Mrp systems. The data suggest that Vc-Mrp operates in a binding exchange mode with all three transported alkali cations competing for the antiporter with protons (fig. 6).

Interestingly, when expressed in a heterologous host, Vc-Mrp not only enhances the resistance of the antiporter-less host cells toward $\mathrm{Na}^{+}$and $\mathrm{Li}^{+}$(fig. 2), but also protects transformants from growth inhibition by added bile salts (fig. 3). Mrp systems belonging to groups 1 [Ito et al., 1999, 2000] and 2 (this work) may thus share the capacity for bile salt efflux. In order to test this notion in direct experiments we will design assays to measure the bile salt transport in everted EP432 vesicles containing Vc-Mrp. It remains possible that the effects of Mrp on bile salt resistance are mediated by indirect effects of antiport on native bile export systems of the $E$. coli host, but earlier studies of Mrp effects on bile salt efflux in B. subtilis support the commonality inferred here.

J Mol Microbiol Biotechnol 2009;16:176-186
The observed differences in $\mathrm{pH}$ optima for the protection against bile salts (neutral pH, fig. 3a) and cation/proton exchange measured in everted vesicles (alkaline $\mathrm{pH}$, fig. 4a) are in agreement with earlier indications of a lack of mechanistic coupling between Mrp-mediated $\mathrm{Na}^{+}$ transport and bile efflux [Ito et al., 2000]. This supports the idea that Mrp systems may in fact be consortia of physically interacting transporters [Swartz et al., 2005a]. There is likely to be some variability in the anion substrates of Mrp as already shown for the cation substrates of Mrp [Swartz et al., 2005a]. Evidence for involvement of Agrobacterium tumefaciens Mrp in arsenite resistance may reflect an efflux capacity of this anion instead of (or in addition to) bile salts in some Mrp systems [Kashyap et al., 2006]. Interestingly, bile and arsenite are both substrates of the BART superfamily of transporters [Mansour et al., 2007], so this particular combination may have arisen multiple times. Vc-Mrp has here been shown to be an attractive model for studying the Mrp family. It will be of interest to use this system to explore the molecular mechanism of Mrp-dependent bile extrusion and its association with one or more particular Mrp proteins.

The $\mathrm{pH}$ optimum of 9-9.5 found here for the Vc-Mrpmediated ion exchange deserves a special consideration. We hypothesize that the physiological value of Vc-Mrp may relate to the ecology of the estuarine environment of $V$. cholerae. Estuaries show large fluctuations in physical properties that arise from variable ratios and rates of mixing of brackish and fresh water [Huq et al., 1984]. $V$. cholerae survives and associates with copepods and plankton but does not grow under many of the conditions found in the estuaries in which it is endemic [Binsztein et al., 2004; Huq et al., 1984; Miller et al., 1984]. The pH optimum of 9-9.5 is within the $\mathrm{pH}$ range reached in estuaries but above the range for $V$. cholerae growth [Miller et al., 1984]. This high $\mathrm{pH}$ optimum is consistent with that of other Mrp systems that are associated with alkali resistance [Hamamoto et al., 1994; Swartz et al., 2005a, 2007]. It is therefore plausible that Vc-Mrp is critical for survival of this pathogen during periods of alkaline swings that occur in the natural setting for a key part of its life cycle. To examine this possibility, it would be interesting to construct a Vc-Mrp knockout mutant of $V$. cholerae and compare its survival to that of the wild-type strain under conditions that mimic the combined estuarine challenges of high $\mathrm{pH}$, low nutrient levels and temperature, sometimes combined with low oxygen content. In view of the $\mathrm{K}^{+} / \mathrm{H}^{+}$antiport capacity of Vc-Mrp shown in this study, $\mathrm{H}^{+}$uptake to support alkali resistance could 
be achieved using the outwardly directed $\mathrm{K}^{+}$gradient when oxygen depletion is encountered in a deep current at alkaline $\mathrm{pH}$.

\section{Experimental Procedures}

\section{Materials}

All chemicals were from Sigma Chemical Co. or Fisher Scientific. Restriction nucleases were from Gibco-BRL, MBI Fermentas or New England Biolabs. Protein content in membrane vesicles was determined by the Bio-Rad Detergent Compatible Protein Assay Kit.

\section{Bacterial Strains and Culture Conditions}

The $\mathrm{Na}^{+} / \mathrm{H}^{+}$antiporter-deficient (melBLid, $\Delta \mathrm{NhaB} 1, \mathrm{cam}^{\mathrm{R}}$, $\Delta$ NhaA1, $k a n^{\mathrm{R}}, \Delta$ lacZY, thrl) strain of E. coli EP432 was kindly provided by Dr. E. Padan (Hebrew University of Jerusalem, Israel). For routine cloning and plasmid construction, E. coli $\mathrm{DH} 5 \alpha$ (US Biochemical Corp.) was used as host. V. cholerae strain used was O395-N1 [Häse and Mekalanos, 1998], which is the classical O395 Ogawa strain with a partial deletion of the ctxAB operon and translational toxT::lacZ fusion (O395N1-TZ) [Häse and Mekalanos, 1998]. If not otherwise indicated, EP432 cells were grown aerobically at $37^{\circ} \mathrm{C}$ in LBK (modified L broth in which $\mathrm{NaCl}$ was replaced by $\mathrm{KCl}$ [Padan et al., 1989]) supplemented with $100 \mu \mathrm{g} /$ $\mathrm{ml}$ ampicillin, $30 \mu \mathrm{g} / \mathrm{ml}$ kanamycin, $17.5 \mu \mathrm{g} / \mathrm{ml}$ chloramphenicol and $0.5 \%(\mathrm{w} / \mathrm{v})$ arabinose. For the phenotype analysis, various concentrations of $\mathrm{NaCl}, \mathrm{LiCl}$ or sodium cholate were added to the LBK medium described above and buffered at desired $\mathrm{pH}$ with 60 $\mathrm{mM}$ of Bis-Tris propane/ $\mathrm{HCl}$. For the induction of the expression of Vc-Mrp, EP432 transformants were grown in LBK at $35^{\circ} \mathrm{C}$ with moderate aeration. At $\mathrm{OD}_{600} \sim 0.200$, $\mathrm{L}$-arabinose was added to a final concentration of $0.5 \%(\mathrm{w} / \mathrm{v})$ and then after $30 \mathrm{~min}$ more, $\mathrm{NaCl}$ was added to a final concentration of $0.3 \mathrm{M}$. Cells were harvested at $\mathrm{OD}_{600}$ of 2.2-2.5 and immediately used for the isolation of vesicles.

\section{Cloning of $V c-m r p$}

Sequence data for $V$. cholerae were from the Institute for $\mathrm{Ge}$ nomic Research website at http://www.tigr.org. The entire $m r p A^{\prime}-$ $G$ region was amplified by PCR from chromosomal DNA of $V$. cholerae $\mathrm{O} 395-\mathrm{N} 1$ as the template and directly cloned into the pBAD-TOPO vector (Invitrogen), yielding pVcMrp construct which was used for the expression studies. Primers used for cloning were: 5'-VCA0157 (TA ATG AAG ACA GGA CTC GAT AAG C) and 3'-VCA0152 (ATA GGC AGC AAA CTA CTT CTG CG).

\section{Isolation of Membrane Vesicles and Assays of Antiport} Activity

Inside-out membrane vesicles were prepared by passing a bacterial suspension through a French press (Aminco) and assayed for cation-proton antiport activities essentially as described previously [Dzioba et al., 2002; Habibian et al., 2005; Ostroumov et al., 2002] with minor modifications. The antiport activities were monitored by the acridine orange ( $\mathrm{AO}$ ) fluorescence dequenching. Vesicles were obtained and stored in a buffer containing 140 $\mathrm{mM}$ choline- $\mathrm{Cl}, 10 \%$ (w/v) glycerol and $20 \mathrm{~mm}$ Tris- $\mathrm{HCl}, \mathrm{pH}$ 7.5. For $\Delta \psi$ measurements, vesicles were isolated in $\mathrm{K}^{+}$-free, $\mathrm{Cl}^{-}$-free buffer where choline- $\mathrm{Cl}$ was substituted by sorbitol. For some experiments, vesicles were isolated in the potassium-rich buffer containing $140 \mathrm{mM} \mathrm{K}_{2} \mathrm{SO}_{4}$ instead of sorbitol.

For $\Delta \mathrm{pH}$ measurements, aliquots of vesicles $(200 \mu \mathrm{g}$ of protein) were added to $2 \mathrm{ml}$ of an assay buffer containing $50 \mathrm{~mm}$ buffer Bis-Tris propane, adjusted to the indicated $\mathrm{pH}, 140 \mathrm{mM}$ choline-Cl, $10 \%$ glycerol (w/v), $10 \mathrm{mM} \mathrm{KCl,} 5 \mathrm{mM} \mathrm{MgSO}_{4}$, and $0.5 \mu \mathrm{M}$ AO. Respiration-dependent formation of the $\Delta \mathrm{pH}$ was initiated by the addition of $10 \mathrm{~mm}$ Tris-D-lactate, and the resulting quenching of $\mathrm{AO}$ fluorescence was monitored with the Shimadzu RF1501 spectrofluorophotometer (excitation at $492 \mathrm{~nm}$ and emission at $528 \mathrm{~nm}$ ). Antiport activity was assessed as the percent of dequenching, i.e., dissipation of the $\Delta \mathrm{pH}$ when test cations were added. $\mathrm{NaCl}, \mathrm{LiCl}$ or $\mathrm{KCl}$ were added: at $10 \mathrm{~mm}$ in the $\mathrm{pH}$-profile determinations; at $0.5-25 \mathrm{mM}$ for the determinations of halfmaximal effective concentrations of $\mathrm{Na}^{+}$or $\mathrm{Li}^{+}$; and at $25-180 \mathrm{mM}$ for the determinations of half-maximal effective concentration of $\mathrm{K}^{+}$. For $\mathrm{K}^{+} / \mathrm{H}^{+}$antiport assays, $\mathrm{KCl}$ was excluded from the experimental medium. The antiport activities are expressed as percent reversal of the lactate-induced fluorescence quenching, as percent of dequenching.

\section{Measurements of Transmembrane Electric Potential \\ Difference}

The $\Delta \psi$-sensitive dye oxonol $\mathrm{V}$ was used to monitor effects of Vc-Mrp-mediated cation-proton antiport on the respiration-generated formation of $\Delta \psi$. In this case, vesicles were prepared in the sorbitol-based experimental medium without $\mathrm{K}^{+}$and $\mathrm{Cl}^{-}$, resuspended in $2 \mathrm{ml}$ of the same medium supplemented with $5 \mathrm{mM}$ $\mathrm{MgSO}_{4}$ and $15 \mathrm{~mm}$ diethanolamine, $\mathrm{pH}$ 9.0, and pre-incubated for $5 \mathrm{~min}$ at room temperature before addition of $1.0 \mu \mathrm{M}$ oxonol $\mathrm{V}$. Excitation was at $595 \mathrm{~nm}$ and emission was monitored at $630 \mathrm{~nm}$. In some experiments, vesicles were isolated and assayed for $\Delta \psi$ in the potassium-rich buffer (described above).

\section{Acknowledgments}

This research was supported by grants from NSERC, Natural Sciences and Engineering Research Council of Canada (to P.D. and J.D.-W.), Ellison Medical Foundation, NIH grant AI-06312001A2 (to C.C.H.), and NIH grant GM28454 (to T.A.K.).

\section{References}

\footnotetext{
Bayer AS, McNamar P, Yeaman MR, Lucindo N, Jones T, Cheung AL, Sahl HG, Proctor RA: Transposon disruption of the complex I NADH oxidoreductase gene (snoD) in Staphylococcus aureus is associated with reduced susceptibility to microbicidal activity of thrombin-induced platelet microbicidal protein 1. J Bacteriol 2006;188:211-222.

- Binsztein M, Costagliola MC, Pichel M, Jurquiza V, Ramirez FC, Akselman R, Vacchino M, Huq A, Colwell R: Viable but nonculturable Vibrio cholerae $\mathrm{O} 1$ in the aquatic environment of Argentina. Appl Environ Microbiol 2004;70:7481-7486.
} 
Dibrov P, Taglicht D: Mechanism of $\mathrm{Na}^{+} / \mathrm{H}^{+}$exchange by Escherichia coli NhaA in reconstituted proteoliposomes. FEBS Lett 1993;336: 525-529.

Dzioba J, Ostroumov E, Winogrodzki A, Dibrov P: Cloning, functional expression in Escherichia coli and primary characterization of a new $\mathrm{Na}^{+} / \mathrm{H}^{+}$antiporter, NhaD, of Vibrio cholerae. Mol Cell Biochem 2002;229:119124.

-Gerchman Y, Rimon A, Venturi M, Padan E: Oligomerization of NhaA, the $\mathrm{Na}^{+} / \mathrm{H}^{+}$antiporter of Escherichia coli in the membrane and its functional and structural consequences. Biochemistry 2001;40:3403-3412.

- Habibian R, Dzioba J, Barrett J, Galperin MY, Loewen PC, Dibrov P: Functional analysis of conserved polar residues in $\mathrm{Vc}-\mathrm{NhaD}, \mathrm{Na}^{+} /$ $\mathrm{H}^{+}$antiporter of Vibrio cholerae. J Biol Chem 2005;280:39637-39643.

-Hamamoto T, Hashimoto M, Hino M, Kitada M, Seto Y, Kudo T, Horikoshi K: Characterization of a gene responsible for the $\mathrm{Na}^{+} / \mathrm{H}^{+}$antiporter system of alkalophilic Bacillus species strain C-125. Mol Microbiol 1994;14: 939-946.

-Harel-Bronstein M, Dibrov P, Olami Y, Pinner E, Schuldiner S, Padan E: MH1, a second-site revertant of an Escherichia coli mutant lacking $\mathrm{Na}^{+} / \mathrm{H}^{+}$antiporters $(\Delta n h a A \Delta n h a B)$, regains $\mathrm{Na}^{+}$resistance and a capacity to excrete $\mathrm{Na}^{+}$in a $\Delta \mu_{\mathrm{H}^{+}}$-independent fashion. J Biol Chem 1995;270:3816-3822.

Häse CC, Mekalanos JJ: TcpP protein is a positive regulator of virulence gene expression in Vibrio cholerae. Proc Natl Acad Sci USA 1998;95:730-734.

-Hiramatsu T, Kodama K, Kuroda T, Mizushima T, Tsuchiya T: A putative multisubunit $\mathrm{Na}^{+} /$ $\mathrm{H}^{+}$antiporter from Staphylococcus aureus. J Bacteriol 1998;180:6642-6648.

-Huang Y, Lemieux MJ, Song J, Auer M, Wang DM: Structure and mechanism of the glycerol-3-phosphate transporter from Escherichia coli. Science 2003;301:616-620.

- Hunte C, Screpanti E, Venturi, M, Rimon A, Padan E, Michel H: Structure of a $\mathrm{Na}^{+} / \mathrm{H}^{+}$antiporter and insights into mechanism of action and regulation by $\mathrm{pH}$. Nature $2005 ; 435$ : 1197-1202.

- Huq A, West PA, Small EB, Huq MI, Colwell RR: Influence of water temperature, salinity, and $\mathrm{pH}$ on survival and growth of toxigenic $\mathrm{Vib}$ rio cholerae serovar 01 associated with live copepods in laboratory microcosms. Appl Environ Microbiol 1984;48:420-424.

Ito M, Guffanti AA, Krulwich TA: Mrp-dependent $\mathrm{Na}^{+} / \mathrm{H}^{+}$antiporters of Bacillus exhibit characteristics that are unanticipated for completely secondary active transporters. FEBS Lett 2001;496:117-120.

Ito M, Guffanti AA, Oudega B, Krulwich TA: $m r p$, a multigene, multifunctional locus in Bacillus subtilis with roles in resistance to cholate and to $\mathrm{Na}^{+}$and $\mathrm{pH}$ homeostasis. J Bacteriol 1999;181:2394-2402.
Ito M, Guffanti AA, Wang W, Krulwich TA: Effects of nonpolar mutations in each of the seven Bacillus subtilis mrp genes suggest complex interactions among the gene products in support of $\mathrm{Na}^{+}$and alkali but not cholate resistance. J Bacteriol 2000;182:5663-5670.

-Ivey DM, Guffanti AA, Zemsky J, Pinner E, Karpel R, Padan E, Krulwich TA: Cloning and characterization of a putative $\mathrm{Ca}^{2+} / \mathrm{H}^{+}$antiporter gene from Escherichia coli upon functional complementation of $\mathrm{Na}^{+} / \mathrm{H}^{+}$antiporter-deficient strains by the overexpressed gene. J Biol Chem 1993;268:11296-11303.

Kajiyama Y, Otagiri M, Sekiguchi J, Kosono S, Kudo T: Complex formation by the mrpABCDEFG gene products, which constitute a principal $\mathrm{Na}^{+} / \mathrm{H}^{+}$antiporter in Bacillus subtilis. J Bacteriol 2007;189:7511-7514.

- Kashyap DR, Botero LM, Lehr C, Hassett DJ, McDermott TR: A $\mathrm{Na}^{+}: \mathrm{H}^{+}$antiporter and a molybdate transporter are essential for arsenite oxidation in Agrobacterium tumefaciens. J Bacteriol 2006;188:1577-1584.

Kitada M, Kosono S, Kudo T: The $\mathrm{Na}^{+} / \mathrm{H}^{+}$antiporter of alkalophilic Bacillus sp. Extremophiles 2000;4:253-258.

Kosono S, Haga K, Tomizawa R, Kajiyama Y, Hatano K, Takeda S, Wakai Y, Hino M, Kudo $\mathrm{T}$ : Characterization of a multigene-encoded sodium/hydrogen antiporter (sha) from Pseudomonas aeruginosa: its involvement in pathogenesis. J Bacteriol 2005; 187:52425248.

Kosono S, Morotomi S, Kitada M, Kudo T: Analyses of a Bacillus subtilis homologue of the $\mathrm{Na}^{+} / \mathrm{H}^{+}$antiporter gene which is important for $\mathrm{pH}$ homeostasis of alkalophilic Bacillus sp. C-125. Biochim Biophys Acta 1999;1409: 171-175.

- Kosono S, Ohashi Y, Kawamura F, Kitada M, Kudo T: Function of a principal $\mathrm{Na}^{+} / \mathrm{H}^{+}$antiporter, ShaA, is required for initiation of sporulation in Bacillus subtilis. J Bacteriol 2000;182:898-904.

- Mansour NM, Sawhney M, Tamang DG, Vogl C, Saier MH Jr: The bile/arsenite/riboflavin transporter (BART) superfamily. FEBS J 2007;274:612-629.

-Miller CJ, Drasar BS, Feachem RG: Response of toxigenic Vibrio cholerae 01 to physicochemical stresses in aquatic environments. J Hyg (Lond) 1984;93:475-495.

-Ohyama T, Igarashi K, Kobayashi H: Physiological role of the chaA gene in sodium and calcium circulations at a high $\mathrm{pH}$ in Eschericha coli. J Bacteriol 1994;176:4311-4315.

-Ostroumov E, Dzioba J, Loewen PC, Dibrov P: D344 and T345 are critical for cation exchange mediated by $\mathrm{NhaD}, \mathrm{Na}^{+} / \mathrm{H}^{+}$antiporter of Vibrio cholerae. Biochim Biophys Acta 2002;1564:99-106.

Padan E, Maisler N, Taglicht D, Karpel R, Schuldiner S: Deletion of ant in Escherichia coli reveals its function in adaptation to high salinity and an alternative $\mathrm{Na}^{+} / \mathrm{H}^{+}$antiporter system(s). J Biol Chem 1989;264:2029720302.
Padan E, Venturi M, Gerchman Y, Dover N: $\mathrm{Na}^{+} /$ $\mathrm{H}^{+}$antiporters. Biochim Biophys Acta 2001; 1505:144-157.

Pinner E, Kotler Y, Padan E, Schuldiner S: Physiological role of $n h a B$, a specific $\mathrm{Na}^{+} / \mathrm{H}^{+}$antiporter in Escherichia coli. J Biol Chem 1993; 268:1729-1734.

-Pinner E, Padan E, Schuldiner S: Kinetic properties of $\mathrm{NhaB}, \mathrm{a} \mathrm{Na}^{+} / \mathrm{H}^{+}$antiporter from Escherichia coli. J Biol Chem 1994;269:2627426279.

- Putnoky P, Kereszt A, Nakamura T, Endre G, Grosskopf E, Kiss P, Kondorosi A: The pha gene cluster of Rhizobium meliloti involved in $\mathrm{pH}$ adaptation and symbiosis encodes a novel type of $\mathrm{K}^{+}$efflux system. Mol Microbiol 1998;28:1091-1101.

-Radchenko MV, Tanaka K, Waditee R, Oshimi S, Matsuzaki Y, Fukuhara M, Kobayashi H, Takabe T, Nakamura T: Potassium/proton antiport system of Escherichia coli. J Biol Chem 2006;281:19822-19829.

-Safferling M, Griffith H, Jin J, Sharp J, De Jesus M, Ng C, Krulwich TA, Wang DN: TetL tetracycline efflux protein from Bacillus subtilis is a dimer in the membrane and in detergent solution. Biochemistry 2003;42:1396913976.

- Saier MH, Eng BH, Fard S, Garg J, Haggerty DA, Hutchinson WJ, Jack DL, Lai EC, Liu HJ, Nusinew DP, Omar AM, Pao SS, Paulsen IT, Quan JA, Sliwinski M, Tseng TT, Wachi S, Young GB: Phylogenetic characterization of novel transport protein families revealed by genome analyses. Biochim Biophys Acta 1999;1422:1-56.

Swartz TH, Ikewada S, Ishikawa O, Ito M, Krulwich TA: The Mrp system: a giant among monovalent cation/proton antiporters? Extremophiles 2005a;9:345-354.

Swartz TH, Ito M, Hicks DB, Nuqui M, Guffanti AA, Krulwich TA: The Mrp $\mathrm{Na}^{+} / \mathrm{H}^{+}$antiporter increases the activity of the malate: quinone oxidoreductase of an Escherichia coli respiratory mutant. J Bacteriol 2005b; 187:388-391.

Swartz TH, Ito M, Ohira T, Natsui S, Hicks DB, Krulwich TA: Catalytic properties of Staphylococcus aureus and Bacillus members of the secondary cation-proton antiporter-3 (Mrp) family are revealed by an optimized assay in an Escherichia coli host. J Bacteriol 2007;189: 3081-3090.

Taglicht D, Padan E, Schuldiner S: Proton-sodium stoichiometry of NhaA, an electrogenic antiporter from Escherichia coli. J Biol Chem 1993;268:5382-5387.

Tzubery T, Rimon A, Padan E: Mutation E252C increases drastically the $\mathrm{K}_{\mathrm{m}}$ value for $\mathrm{Na}^{+}$ and causes an alkaline shift of the $\mathrm{pH}$ dependence of NhaA Na${ }^{+} / \mathrm{H}^{+}$antiporter of Escherichia coli. J Biol Chem 2004;279:32653272 .

Dzioba-Winogrodzki/Winogrodzki/ Krulwich/Boin/Häse/Dibrov 